\title{
Health risk assessment of heavy metal exposure to classroom dust in primary school, Serdang (Malaysia)
}

\begin{abstract}
Investigation of indoor dust is one of the major pathways in children exposure to heavy metal. High concentration of heavy metal in dust will have significant unequivocal ecological impacts and pose a potential health hazard. Dust samples were collected from seven randomly selected classrooms using a clean plastic brush and shovel. The dust samples were digested using aqua regia method and analyzed for $\mathrm{Cd}, \mathrm{Pb}$ and $\mathrm{Cu}$ using Flame Atomic Absorption Spectrophotometer. Non-cancer effects due to heavy metal exposure from the classroom dust were also assessed. The heavy metal concentrates found on the floor, fan and

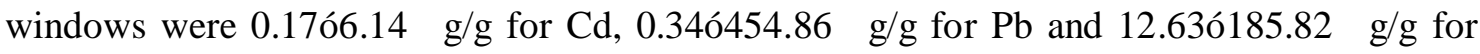
$\mathrm{Cu}$, respectively. In comparison to other reported studies in the literature, the maximum levels of $\mathrm{Cd}, \mathrm{Pb}$ and $\mathrm{Cu}$ were comparable or lower to those reported elsewhere. According to the calculation on Hazard Quotient (HQ) in the case of non-cancer effects, primary school children are experiencing no adverse effects since.
\end{abstract}

Keyword: Classroom; Dust; Heavy metal; Inhalation; Hazard quotient 